\title{
Using Spatial Covariance Function for Antitrust Market Delineation
}

\begin{abstract}
In this paper, we present an application of the estimation of a Spatial Covariance Function in determining the relevant geographic market for a merger. We applied this methodology on the case of a proposed marger between two competing supermarket chains in Brazil. During this application, we first indicate the shortcomings of the analysis carried out by the Brazilian Antitrust System on its evaluation of the merger. This analysis decreed the geographic dimension of the relevant market to be separated on each of the municipalities on the shore of the Sao Paulo state. Our results, using the estimated spatial covariance function using data on 22 products in 43 supermarkets, indicate a single geographic market for all cities.
\end{abstract}

Resumo: Neste artigo, apresentamos uma aplicação de estimativa de uma Função de Covariância Espacial para a determinação do mercado relevante geográfico para uma fusão. Nós aplicamos esta metodologia para uma fusão proposta entre duas cadeias de supermercados no Brasil. Ao longo desta análise, nós inicialmente indicamos as limitações da análise realizada pelo Sistema Brasileiro de Defesa da Concorrência durante a sua avaliação da fusão, que indicava que a dimensão geográfica do mercado se limitava a cada um dos municípios no litoral sul do Estado de São Paulo. Os nossos resultados, obtidos a partir da função de covariância espacial e utilizando dados de 22 produtos em 43 supermercados, indicam a existência de um único mercado relevante abrangendo todas as cidades.

JEL Codes: K21, C31

Keywords: Geographic Markets; Spatial Covariance Function; Merger Control

Palavras-Chave: Função Covariância Espacial: Análise de Fusões.

\section{Área 7: Microeconomia, Métodos Quantitativos e Finanças}




\section{Introduction}

The analysis of mergers relies on a great extent on determining on which markets the resulting entity can exercise an eventual market power. Furthermore, given the emprasis the economist gives to the study of markets, it is to be expected that economic theory would have a satisfactory reply to the questions regarding the setting of bounadries for these markets. However, in applied settings, many different techniques have been used, relying on different types of assumptions on the competitive structure of the markets involved, on the statistical properties of the data at hand and on the judgment of the analyst. This paper aims to contribute to the debate by presenting a new technique can be used on the setting of the relevant market boundaries for a proposed merger, based on computation of the spatial correlation function, developed in Cressie (1993), Conley and Topa (2002) and Chen and Conley (2001). These papers measure the correlation between realizations of random variables as a function of a distance, measured according to a properly determined metric.

To better position our contribution to this literature, the starting point of this paper is by reviewing the procedures currently used on the setting of boundaries of relevant geographic markets. The most important concept used by antitrust authorities on applied merger analysis is the market power concept: the capacity a company has to unilaterally increase its prices after a merger operation. In order to make this concept operational, the first question to be addressed is: what constitutes the relevant market for this merger operation? In other words, if this merger could possibly pose the threat of unilateral exercise of market power, on which market this power would be exercised?

To answer that question, usually two dimensions of this relevant market are considered: the product dimension and the geographic dimension. These dimensions are defined using the socalled SSNIP (Small, but Significant and Non-transitory Increase in Prices) test, which implies the product and geographic markets are the minimum set of substitute products and geographic area which could act a competitive check to an unilateral increase in prices of a given percentage ${ }^{1}$.

There is a number of techniques available for this task. One of the first tecnhiques proposed to deal with this problem evaluates the product flows between different areas; if one does find that the flows of the product coming from outside a given geographic area are responsible for a small part of the consumption there, one does have evidence against the hypothesis this area is part of a larger geographic market. The second part of the test - considered by Elzinga and Hogarty $(1973,1978)$ to be enough for the setting of marketr boundaries - is to evaluate if the shipments to outside this geographic area account for a small part of the production carried out there. If so, this region can be considered a separate geographic market. This approach came under criticism

\footnotetext{
${ }^{1}$ Competitive check meaning the company who tries to increase its prices by that amount finds it unprofitable to do so. A survey on the theme is found in Motta (2004, cap.2).
} 
from Stigler and Sherwin (1985, p. 555), who point out the existence or not of significant product flows between regions does not imply they belong to the same market, in the sense the producers in one region act as a competitive check eliminating persistent price differences. They mentioned the fact that, even two regions belonging to different geographic markets could present large trade flows and, because of price discrimination - say, due to different demand elasticities - one could observe different prices. Furthermore, even if we do not find any flow between these two regions, it does not warrant they are different markets; it is possible the producers in one region pose such a competitive constraint on the other's that we observe the same price in both regions but no shipments between them.

The second approach for the determination of market boundaries tries to estimate the elasticities $^{2}$ for a given product. On this approach, some authors (Werden (1998)) favor the use of the own-price elasticity of demand. Their reasoning is based upon the fact, derived from traditional economic theory, there is a boundary on the own price elasticity of demand that makes it unprofitable for a producer in a given geographic area unilaterally increase its prices. That boundary - called critical elasticity of demand - depends on both the margins these products earn and the hypothetic price increase defined on the SSNIP test. Another point of view on this approach involves the computation of the elasticity of the residual demand (Werden and Froeb (1993) and Sheffman and Spiller (1987)). The elasticity of the residual demand differs from the traditional price elasticity of demand in which it already considers all the effects of all competitors' responses to a given increase in prices by a producer. The empirical implementation of this technique demands both the setting up of a structural model for the competition and the determination of a set of instrumental variables for the estimation of the aforementioned elasticity.

The final way by which elasticities are used on the setting of relevant market boundaries involves the estimation of cross-price demand elasticities. These estimates, which are expected to measure how much - as a percentage - the quantity demanded of a product changes in response to a given percentage increase on the price of another product, could provide a map on which regions could provide a competitive check on price increases by some producers. For instance, if one does find a positive elasticity between the price of a given product sold on the region $\mathrm{A}$ and the price of the same product sold on the region $B$, it might mean the producers on the region $B$ can act as competitive constraint on the behavior of those on region $\mathrm{A}$.

The "might" on the previous paragraph is due to a potential pitfall all these approaches suffer - the so-called cellophane fallacy. This fallacy follows from the fact these estimates are based on the prices collected at the moment of the investigation. However, the SSNIP test mentions a hy-

\footnotetext{
${ }^{2}$ Elasticity is a measure - adimensional - that gives the percentage change on the demanded quantity of a product in response to a given percentage change on other economic variable. The most common elasticities are the own price elasticitiy (measuring the sensitivity of the quantity demanded to changes in its own price), the cross price (measuring the sensitivity to changes in the prices of other products) and income elasticity (the sensitivity to changes in the income).
} 
pothetical price increase from the price levels that would be verified under competitive conditions. As reported by Motta (2004, p. 105), the US Supreme Court determined the market for cellophane relevant for a proposed merger involving U.S. DuPont should include other flexible wrapping materials, given the high cross elasticity of demand between cellophane and these wrapping materials. This decision was criticized on the grounds that such high cross price elasticity was in itself a result of market power, by which DuPont increased its prices until other products started to consider other wrapping materials as substitutes.

The third approach on setting the boundaries of relevant makets is based on the concept summarized by Stigler and Sherwin (1985, p. 555):

"Consider the basic definition of a market: 'A market for a good is the area within the price of a good tends to uniformity, allowance made for transportation costs.' If there is a single price (allowing for transportation costs) over a given area, that must mean that either buyers or sellers (or both) can and do consider transactions at any point within the area to be an excellent (in the limit, a perfect) substitute for transactions at other points within the area. Hence, the market area embraces the buyers who are willing to deal with any seller, or the sellers who are willing to deal with any buyer, or both." 3

This quotation sums up the reason for the usage of price correlations as a way to determine the geographic dimensions of a market, as in Stigler and Sherwin (1985) and Horowitz (1981). If we have a set of locations denoted by $\mathbf{S}=\left\{s_{1}, s_{2}, \ldots s_{n}\right\}$ corresponding to the locations of $n$ sellers, and the prices charged by all these sellers indexed by $\mathbf{P}=\left\{P_{s 1}, P_{s 2}, \ldots, P_{s n}\right\}$ and we find that $\operatorname{Cov}\left(P_{s i}, P_{s k}\right)>0$, we expect the producers $i$ and $k$ to be in the same market. On the other hand, if we find that $\operatorname{Cov}\left(P_{s i}, P_{s k}\right)=0$, this might be interpreted as the producers $i$ and $k$ do not belong in the same market.

Slade (1986) points out that correlations might be spuriously high, if one does not control for the impact of other factors that impact the behavior of the prices at different locations, or induce stochastic trends on the behavior of the prices. The author uses Granger causality tests to address some of this problem. A very thoughtful critique of the usage of price correlation tests on market analysis on antitrust is given by Werden and Froeb (1993). Their critique is based on the fact the price correlation tests are carried out without regard to an explicit modelling of the consumers' choices, and that an informed application of economic theory underlining the SSNIP test could present better results, and recommend the usage of residual demand elasticities as a tool for determining such boundaries.

Sherwin (1993), in a comment to the paper by Werden and Froeb on the same issue they present their critique, replies by pointing out the implementation of the SSNIP test Werden and Froeb

\footnotetext{
${ }^{3}$ The quotation used by Stigler and Sherwin on the excerpt above is from Cournot, and taken by Marshall.
} 
(1993) propose is also fraught with difficulties, and the fact the authors do not provide conclusive evidence concerning the superiority of their proposal over price correlation tests. Finally, Sherwin (1993) also points out Werden and Froeb (1993) proposal requires a higher degree of economic analysis in order to identify the structure of competition on the market under scrutiny, thus giving subsdies to econometrically building a structural model in order to get estimates to the relevant residual demand elasticities. As Sherwin (1993, p. 356) points out:

"Such an approach ignores the fundamental purpose of the Guidelines in the first place, that is, to give guidance to those contemplating mergers and acquisitions. Indeed, why have the Guidelines at all? Instead, a fact-intensive economic analysis (whatever that means) could simply be used to evaluate directly the ultimate question of whether prices are likely to rise as a result of a merger. Why bother with market delineation and market share calculations, which are, after all, only intermediate inquiries?"

This quotation sums up the point that, even though sometimes it is required the use of a structural model to estimate price correlations, usually it is not required the setting up of a full economic model of the competition on the market in order to get statistically consistent estimates of the relevant parameters. This point also underlies our choice of technique - spatial covariance function - for establishing the boundaries of the relevant markets. We will discuss the theoretical aspects of the estimation of such functions on the next section.

\section{Spatial Covariance Function}

The responses by Sherwin (1993) to the criticisms posed by Werden and Froeb (1993) allow us to set a criterion for the setting of a relevant geographic market for a proposed merger. It indicates the geographic market as the area for which we will find significant correlation between the prices for the products sold in this area, and we find non-significant correlaitions for the products sold outside of this area.

However, we have a problem with the application of this concept: we may not have data on every location needed for determining the market boundary. For instance, if we do find a positive covariance between the prices in two locations, $s_{i}$ and $s_{j}$ and we do not find a positive covariance between the prices recorded at $s_{i}$ and $s_{k}$, we only know the market boundary lies between $s_{j}$ and $s_{k}$, but not where. To overcome these difficulties, and still be consistent with the principle set forth above, we propose the use of the spatial covariance function as a guideline for setting the limits of the relevant market. This function can be denoted as $C(\|\tau\|)$ and expresses the covariance between the variables as a function of the distance between the distance between them - expressed as $\|\tau\|$. 
This spatial covariance function can be estimated non-parametrically by the local averaging method of Conley and Topa (2002) or by a shape preserving cardinal B-spline sieve, as used in Chen and Conley (2001). Both of them assume the locations of the agents are exogenous to the data generating process of the variable studied, the variable to be stationary and isotropic ${ }^{4}$. The shape preserving cardinal B-spline wavelet sieve, which will be used on this paper, is a special case of the method of sieves (Grenander (1981)). They consist on using a sequence of parametric families - in our case, the B-spline sieve - to approximate unknown functions. The unknown function we are trying to approximate is the analogous of the spectral measure for covariance stationary time series (Chen and Conley (2001)), denoted by $\Phi(y)$. The approximation is as follows:

$$
\begin{aligned}
\Phi(y) & \approx \sum_{j=-\infty}^{+\infty} b_{j} B_{m}\left(2^{n} y-j\right) \\
B_{m}(x) & =\frac{1}{(1-m) !} \sum_{k=0}^{m}(-1)^{k}\left(\begin{array}{c}
m \\
k
\end{array}\right)[\max (0, x-k)]^{m-1}
\end{aligned}
$$

Given this approximation for the $\Phi(y)$ function, we could estimate the spatial covariance function as c, computed as follows:

$$
\mathbf{c}=\left\{\begin{array}{c}
C(\|\tau\|)=\int_{0}^{\infty} h(y\|\tau\|) d \Phi(y): \Phi(y) \text { bounded, positive nondecr. } \\
C \text { continous at } 0, \text { has } m_{c} \text { derivatives }
\end{array}\right\}
$$

On the function above, $\|\tau\|$ denotes the euclidean distance ${ }^{5}$. The $h(y\|\tau\|)$ function is defined as follows:

$$
h(y\|\tau\|)=2^{(k-2) / 2} \Gamma\left(\frac{k}{2}\right) \frac{J_{(k-2) / 2}(y(\|\tau\|))}{y(\|\tau\|)^{(k-2) / 2}}
$$

In which $k$ is the dimension of the $C(\|\tau\|)$ vector, and the $\Gamma($.$) denotes the Gamma function:$

$$
\Gamma(n)=\int_{0}^{\infty} t^{n-1} e^{-t} d t
$$

The $J_{(k-2) / 2}($.$) denotes the Bessel function, which can be approximated, for small values of its$ argument, by:

$$
J_{n}(x) \sim \frac{1}{2^{n} n !} x^{n}
$$

Given those estimates, the next point is to determine confidence intervals for those estimated covariances. The confidence intervals, as shown on the paper by Chen and Conley (2001), are derived for any desired level of confidence by bootstrapping. This non-parametric estimation presents some advantages to the most common technique used on spatial econometrics analyses - the Spatial Au-

4 That means the correlation between the realizations of the variable in two locations depends only on the distance between them and not on direction.

${ }^{5}$ For details, see Chen and Conley (2001). 
toregressive (SAR) Model or the Conditionally Autoregressive (CAR) Model. Both models model the spatial dependence as a function of two elements: a neighbor matrix, usually denoted $\mathbf{W}$, and a spatial correlation parameter, commonly denoted $\rho$. Wall (2004) finds some puzzling results on the application of this model on a quite simple setting, such as non-robustness of the results on the definition of the $\mathbf{W}$ matrix. In other words, small errors on the definition of the neighborhood matrix implies in large changes on the estimated spatial covariances.Furthermore, Wall (2004) finds out that the ordering of the spatial correlations does change as the spatial correlation parameter changes within the allowed range required to estimate the spatial correlations. Both problems does not exist on the methodology set forth above, which gives results robust to small errors on the recording of the distances between agents (Conley (1999)). The next section presents an application os this methodology for an antitrust case involving supermarkets.

\section{Application: the Brazilian Supermarkets}

In February 03, 1999 two supermarket companies, CBD $^{6}$ and PERALTA sumbitted a memorandum to the Brazilian Antitrust System in which CBD expressed its intent to purchase thirty eight supermarkets and one warehouse belonging to the PERALTA chain. The supermarkets involved on this operation were located on the following municipalities:

Table 1: Supermarkets (PERALTA) and Cities

\begin{tabular}{cccc}
\hline City & Supermarkets & City & Supermarket \\
\hline Sao Paulo & 9 & Praia Grande & 4 \\
Cubatao & 3 & Sao Bernardo do Campo & 1 \\
Santos & 7 & Itapecerica da Serra & 1 \\
Mongagua & 1 & Caraguatatuba & 1 \\
Guaruja & 3 & Guarulhos & 1 \\
Peruibe & 1 & Sao Sebastiao & \\
Itanhaem & 1 & & \\
\hline
\end{tabular}

The Brazilian Antitrust System is composed of two Commissions, one of them affiliated with the Finance Ministry $\left(\mathrm{SEAE}^{7}\right)$, and another one associated with the Ministry of Justice $\left(\mathrm{SDE}^{8}\right)$. They are in charge of investigating the proposed merger and issuing a opinion on which points are to be blocked and which remedies are proposed. The opinion goes to the deciding body $\left(\mathrm{CADE}^{9}\right)$, whose judges have the final ruling. The memo was received by the commission associated with the Ministry of Justice (SDE), and carried out an analysis of the proposed merger, to be submitted to CADE.

\footnotetext{
6 Acronym for its Portuguese name, Companhia Brasileira de Distribuicao.

7 In Portuguese, Secretaria Especial de Acompanhamento Economico.

8 Acronym for its Portuguese name, Secretaria de Direito Economico.

${ }^{9}$ In Portuguese, Conselho Administrativo de Defesa Economica.
} 
On its analysis of the geographic dimension of the relevant market for this operation, the SDE chose to use different criteria, taking into account the fact the supermarkets were located on cities of differing sizes, from Sao Paulo - one of the largest cities in the world - to cities with less than one hundred thousand inhabitants. For cities with more than one million inhabitants, the Antitrust Authority relied on a study commissioned by the Brazilian Supermarkets' Association, which purported to describe the area capable of attracting about $70 \%$ of the customers of a given store. For supermarkets with more than 20 check-outs, the study indicated this area is of about 2,5 kilometers, and for supermarkets with more than 40 check-outs, this area was set at 5 kilometers. These values were used to establish the relevant geographic markets. For cities with less than one million inhabitants, the Authority defined the relevant geographic market as the boundaries of the municipality.

Based on these concepts, SDE issued an opinion the entity resulting from the merger has market power on five cities located on the southern shore of the State of Sao Paulo: Cubatao, Sao Vicente, Guaruja, Itanhaem and Praia Grande. These cities are shown on the map below:

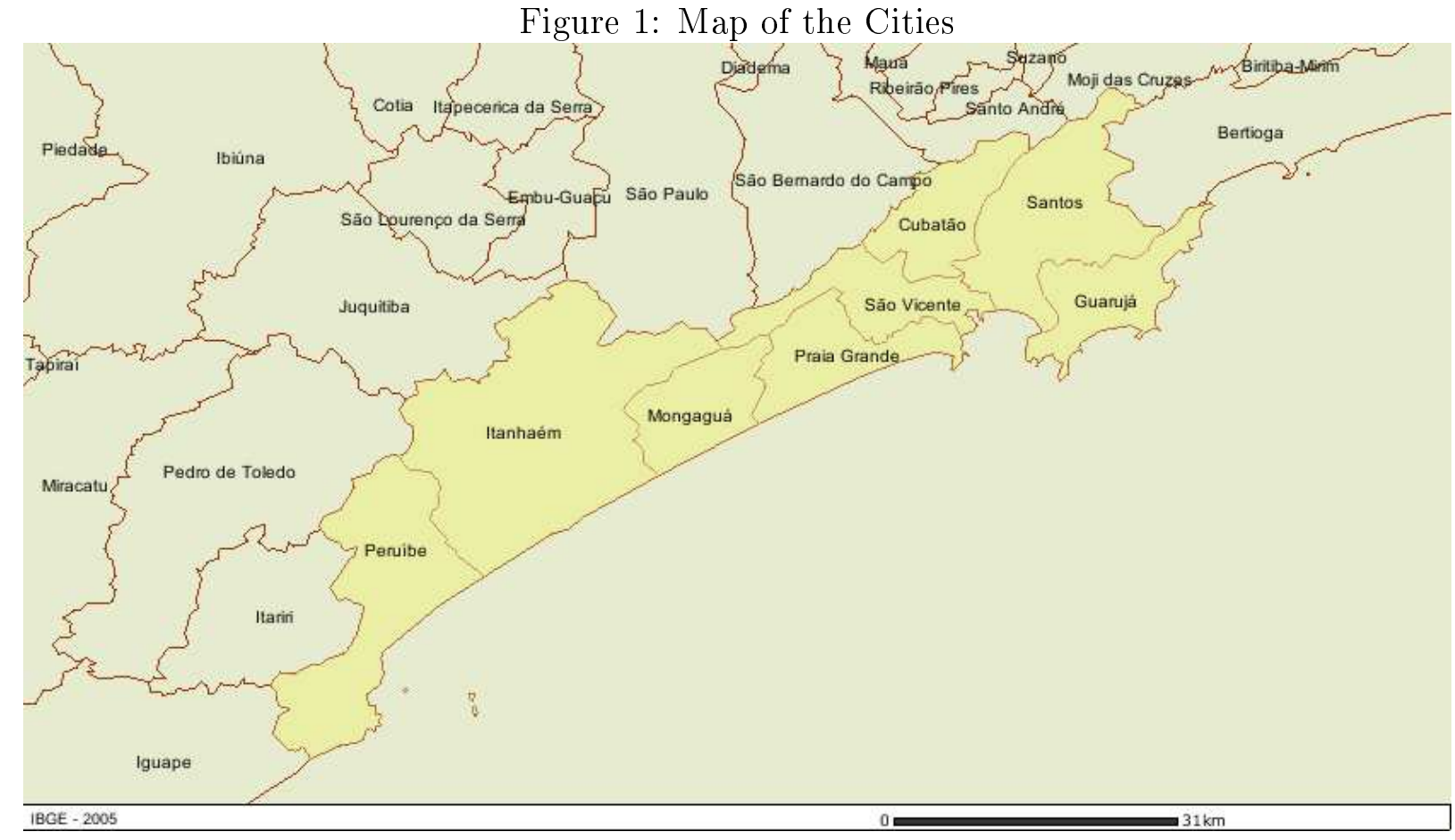

Source: Brazilian Geographic and Statistics Institute (IBGE).

Considering these markets, the SDE issued an opinion to the deciding body requiring CBD to divest one of its supermarkets on the city of Cubatao, disregarding the fact that the consumer who defines the geographic relevant market is not the average, but the marginal one, who is indifferent between consuming on one store or another. That consumer is the one relevant for the pricing decision of the "hypothetical monopolist" used on the Merger Guidelines applied by almost every 
one of the Antitrust Authorities in the world. Even if $70 \%$ of the consumers of a given supermarket are located in a perimeter of 5 kilometers around a given supermarket, one can easily deduce that, for given demand configuration, a hypothetical monopolist refrains from increasing its prices even if the the same share of customers keep going to the same supermarket. Considering the inadequacies of the geographic market definition espoused by the Authority, the next step is to determine it empirically. This will be the subject of the following sections.

\subsection{Data Analysis}

In order to investigate the hypothesis put above, we had data on 44 supermarkets, whose geographical locations and ownership are presented on the Appendix 1 and are depicted on the following picture:

Figure 2: Geographic Locations of the Supermarkets

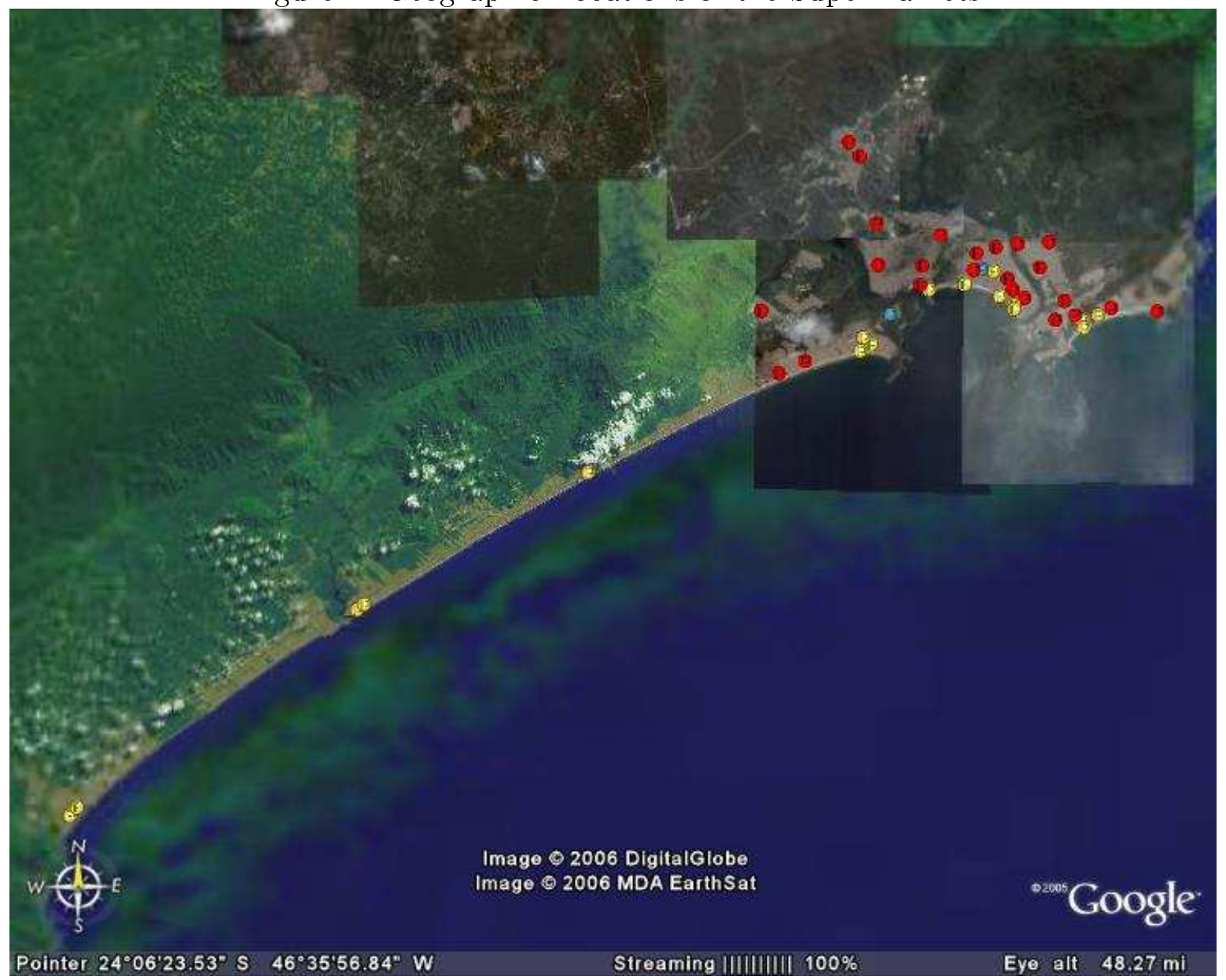

This spatial configuration was used to compute the distances - in kilometers - between supermarkets, which are depicted on the picture on the Appendix 2. This is such that the minimum distance between two supermarkets is about 200 meters and the longest distance is just over 93 kilo- 
meters. For each supermarket, we had data on the 500 products with most sales in BRL (Brazilian Reais), for a period of fourteen months between January, 2003 and February 2004. However, these 500 products were not the same in each location; thus, we had to select some of them to carry out our analysis. The selected products, chosen because they appeared on the greatest number of months on the greatest number of supermarkets, are as follows ${ }^{10}$ :

\section{Table 2: Selected Products}

\begin{tabular}{lcc}
\hline \hline Product & Brand & Package Size \\
\hline Hot Chocolate Mix & Toddy & $400 \mathrm{~g}$ \\
Refined Sugar & Uniao & $1 \mathrm{Kg}$ \\
Rice & Tio Joao & $5 \mathrm{Kg}$ \\
Crackers & Club Social & $279 \mathrm{~g}$ \\
Coffee & Pilao & $500 \mathrm{~g}$ \\
Beer & Bavaria & $350 \mathrm{ML}$ \\
Beer & Brahma & $350 \mathrm{ML}$ \\
Beer & Kaiser & $350 \mathrm{ML}$ \\
Chocolate & BIS & $150 \mathrm{~g}$ \\
Meat & & $\mathrm{Kg}$ \\
Detergent & OMO & $1 \mathrm{Kg}$ \\
Poultry & & $\mathrm{Kg}$ \\
Milk & Parmalat & $1 \mathrm{~L}$ \\
Condensed Milk & Moca & $395 \mathrm{~g}$ \\
Mayonnaise & Hellman's & $500 \mathrm{~g}$ \\
Margarine & Qualy Crem & $500 \mathrm{~g}$ \\
Watermelon & & $\mathrm{Kg}$ \\
Tomato Sauce & Pomarola & $340 \mathrm{~g}$ \\
Mozzarela & & $\mathrm{Kg}$ \\
Cheese & & $\mathrm{Kg}$ \\
Soft Drink & Guarana & $2 \mathrm{~L}$ \\
Soft Drink & Coca-Cola & $350 \mathrm{ML}$ \\
\hline \hline
\end{tabular}

For each of the products, the spatial covariance was calculated as a function of distance. The covariances obtained were normalized by dividing it by the global variance ${ }^{11}$. A graphical example of the estimates - for product 2, Uniao Refined Sugar - is presented on the Appendix 3, and values for some distances are presented on the table below:

\footnotetext{
${ }^{10}$ Their descriptive statistics are presented on Appendix 4.

11 That means, the variance of all observations on the selected product for all supermarkets and months. The rationale for this normalization is as such. Under the current model, the deviations from the means, denoted $\mathbf{u}$, could be decomposed into two components, one collecting the spatially determined aspects of the variable (denoted $\theta$ ), and another one the random components (denoted $\epsilon$ ). Thus, we can write this relation as:

$$
\mathbf{u}=\theta+\epsilon
$$

The normalization described on the text means the spatial covariance converges to the spatial correlation coefficient if $\theta$ corresponds to a larger fraction of the total variance of $\mathbf{u}$ then $\epsilon$. All estimates were carried out using the MATLAB software, version 7.0.1. The code used on all estimates is available upon request
} 
Table 3: Spatial Covariance Estimates

\begin{tabular}{l|cccccc}
\hline \hline Products & \multicolumn{6}{|c}{ Distance - in Km } \\
& 0.22 & 10.0 & 20.1 & 30.2 & 50.1 & 92.0 \\
\hline 1 & 0.59947 & 0.60742 & 0.74686 & 0.85524 & 0.5822 & 0.80014 \\
2 & 0.94081 & 0.93437 & 0.93543 & 0.96521 & 1.0028 & 0.9571 \\
3 & 0.88844 & 0.91314 & 0.92393 & 0.90762 & 0.92458 & 0.88782 \\
4 & 0.57532 & 0.5852 & 0.66484 & 0.64201 & 0.28372 & 0.57744 \\
5 & 0.42362 & 0.5572 & 0.45214 & 0.23734 & 0.4155 & 0.39352 \\
6 & 0.53426 & 0.57355 & 0.61191 & 0.63996 & 0.4736 & 0.57643 \\
7 & 0.45879 & 0.45955 & 0.41168 & 0.4696 & 0.47414 & 0.43027 \\
8 & 0.44943 & 0.49344 & 0.45199 & 0.48934 & 0.37327 & 0.36969 \\
9 & 0.68389 & 0.71559 & 0.66271 & 0.71299 & 0.56572 & 0.51792 \\
10 & 0.72434 & 0.71683 & 0.69866 & 0.62802 & 0.56077 & 0.70425 \\
11 & 0.51007 & 0.48723 & 0.47272 & 0.58807 & 0.54808 & 0.54028 \\
12 & 0.76443 & 0.7742 & 0.79727 & 0.79434 & 0.71347 & 0.7695 \\
13 & 0.76177 & 0.78738 & 0.78833 & 0.86001 & 0.92414 & 0.80056 \\
14 & 0.53998 & 0.49633 & 0.49878 & 0.5628 & 0.51204 & 0.5267 \\
15 & 0.38283 & 0.41068 & 0.47144 & 0.44311 & 0.41565 & 0.39502 \\
16 & 0.60658 & 0.5802 & 0.61612 & 0.63633 & 0.53561 & 0.73912 \\
17 & 0.77716 & 0.77615 & 0.72515 & 0.7447 & 0.85412 & 0.78834 \\
18 & 0.49783 & 0.5991 & 0.65854 & 0.82389 & 0.60629 & 0.49433 \\
19 & 0.44718 & 0.4698 & 0.50278 & 0.56978 & 0.41909 & 0.41138 \\
20 & 0.56647 & 0.50989 & 0.55559 & 0.59291 & 0.47336 & 0.57242 \\
21 & 0.62413 & 0.64224 & 0.56374 & 0.54167 & 0.65542 & 0.59559 \\
22 & 0.47898 & 0.51001 & 0.5685 & 0.59343 & 0.48683 & 0.48299 \\
\hline \hline
\end{tabular}

Every one of the estimates above are outside of the bootstrapped $95 \%$ confidence region, indicating we can reject the hypothesis of non-correlation between prices at locations separated by these distances. Considering what we have posed before, this indicates the decision the SDE made regarding the geographic market definition is incorrect.

However, some other points must be addressed before a final conclusion can be presented. Some extensions of this result are presented on the following section.

\subsection{Extensions}

Despite indicating the relevant market is composed of all the cities mentioned above, these results must be further refined, for they could be subject of criticism from diffierent points of view. The first one pertains to the fact the products in the sample - being one of the 500 products with the most sales for each product - are the result of a distribution process and marketing campaigns defined at the level of supermarket chain. Even the Brazilian Antitrust Authority, on its final report for the decision body, mentioned a study in Kwoka and White (2003), mentioning that only $1,5 \%$ of the products sold by the Toys ' $R$ ' Us retailer were priced according to the local conditions.

Another important criticism, coming from a point of view, pertains to the fact local stores could select its protfolio of goods sold, and this portfolio could be a strategic variable for the competition between supermarkets; thus, the covariance could be biased due to the omission of 
relevant variables. And finally, the pricing decisions of the companies might be affected by the socio-economic characteristics of the cities - or neighborhoods - in which the supermarkets are located.

In order to address these criticisms, we extended our analysis, in which we were forced to adopt some simplifying assumptions. The first one is that the geographic location decisions are exogenous to the pricing decisions ${ }^{12}$. The second one is that the marketing and distribution policies are decided on the level of the chain, and these decisions are constant throghout the period of analysis. Finally, we assume the socio-demographic characteristics of the cities to be constant during this period, also.

These assumptions allow us to model this characteristics as fixed effects for each supermarket chain and city, leading to the following model for each of the prices:

$$
P_{i t}=\alpha_{0}+\beta_{1} C H A I N_{i t}+\beta_{2} V A C A T I O N_{i t}+\sum_{k=1}^{6} \gamma_{k} D_{k i t}+\varepsilon_{i t}
$$

On which $P_{i t}$ refers to the price of any of the products selected on the supermarket $i$ at time period $t, C H A I N_{i t}$ is a dummy with the value of one for the supermarkets belonging to the CBD chain and zero otherwise. The $D_{k i t}$ denotes a set of six dummies for the cities of Sao Vicente, Guaruja, Santos, Praia Grande, Cubatao and Peruibe. The VACATION $N_{i t}$ variable is another dummy variable, intended to capture the effects on the prices due to the holiday season (from December to February). The cities involved on this case are beach cities not far from the largest city in Brazil, Sao Paulo, and important tourist destinations. The regression results ${ }^{13}$ for each of the products are on the table below:

Table 4: Regression Results

\begin{tabular}{|c|c|c|c|c|c|c|c|c|c|c|c|c|c|c|c|c|c|}
\hline \multirow{2}{*}{$\begin{array}{l}\text { Product } \\
1\end{array}$} & \multicolumn{2}{|c|}{ Constant } & \multicolumn{2}{|c|}{ CHAIN } & \multicolumn{2}{|c|}{ Guaruja } & \multicolumn{2}{|c|}{ Praia Grande } & \multicolumn{2}{|c|}{ Peruibe } & \multicolumn{2}{|c|}{ Sao Vicente } & \multicolumn{2}{|c|}{ Santos } & \multicolumn{2}{|c|}{ VACATION } & \multirow{2}{*}{$\begin{array}{r}R^{2} \\
0.180\end{array}$} \\
\hline & 3.222 & ** & 0.003 & & 0.160 & $* *$ & 0.202 & ** & 0.216 & $*$ & 0.101 & & 0.041 & & -0.352 & ** & \\
\hline 2 & 1.165 & ** & 0.012 & & 0.028 & & 0.051 & * & 0.033 & & 0.028 & & 0.022 & & -0.137 & $* *$ & 0.158 \\
\hline 3 & 9.776 & $* *$ & 0.041 & & 0.190 & & 0.202 & & 0.149 & & 0.219 & & 0.205 & & 0.205 & $* *$ & 0.013 \\
\hline 4 & 2.085 & ** & 0.012 & & 0.122 & ** & 0.192 & ** & 0.140 & ** & 0.172 & $* *$ & 0.133 & $* *$ & -0.183 & $* *$ & 0.205 \\
\hline 6 & 0.724 & $* *$ & 0.017 & ** & 0.035 & $* *$ & 0.060 & $* *$ & 0.031 & $* *$ & 0.042 & $* *$ & 0.030 & $* *$ & -0.019 & $* *$ & 0.111 \\
\hline 7 & 0.905 & $* *$ & 0.010 & * & 0.031 & ** & 0.044 & ** & 0.029 & ** & 0.034 & $* *$ & 0.026 & $* *$ & 0.010 & $* *$ & 0.064 \\
\hline 8 & 0.760 & ** & 0.009 & ** & 0.028 & ** & 0.038 & ** & 0.026 & ** & 0.025 & $* *$ & 0.025 & $* *$ & -0.031 & $* *$ & 0.163 \\
\hline 9 & 2.439 & ** & 0.042 & * & 0.084 & ** & 0.152 & ** & 0.243 & ** & 0.114 & $* *$ & 0.047 & & -0.224 & $* *$ & 0.269 \\
\hline 10 & 9.212 & ** & -0.464 & ** & -0.630 & ** & -0.681 & ** & -0.610 & ** & -0.858 & $* *$ & -0.553 & $* *$ & 0.920 & $* *$ & 0.236 \\
\hline 12 & 2.242 & ** & 0.018 & & 0.088 & ** & 0.097 & ** & 0.030 & & 0.063 & & 0.045 & & 0.048 & $* *$ & 0.035 \\
\hline 13 & 1.472 & $* *$ & 0.022 & * & 0.044 & ** & 0.057 & ** & 0.033 & & 0.041 & $* *$ & 0.027 & & -0.060 & $* *$ & 0.110 \\
\hline 14 & 1.697 & ** & 0.032 & $* *$ & 0.095 & $* *$ & 0.126 & $* *$ & 0.107 & $* *$ & 0.111 & $* *$ & 0.069 & $* *$ & -0.115 & $* *$ & 0.271 \\
\hline 15 & 3.475 & $* *$ & 0.020 & & 0.154 & $* *$ & 0.189 & $* *$ & 0.125 & $* *$ & 0.160 & $* *$ & 0.117 & $* *$ & 0.047 & $* *$ & 0.105 \\
\hline 16 & 2.834 & $* *$ & -0.024 & & 0.002 & & 0.016 & & -0.038 & & -0.055 & & -0.040 & & -0.002 & & 0.022 \\
\hline 17 & 0.567 & $* *$ & 0.000 & & 0.002 & & 0.031 & & 0.027 & & 0.011 & & 0.014 & & 0.003 & & 0.010 \\
\hline 18 & 1.342 & $* *$ & -0.011 & & -0.003 & & -0.015 & & 0.053 & & 0.012 & & 0.006 & & 0.092 & $* *$ & 0.098 \\
\hline 19 & 10.552 & $* *$ & 0.043 & & 0.123 & & 0.336 & * & -0.478 & * & -0.382 & * & -0.142 & & -0.215 & * & 0.048 \\
\hline 20 & 11.224 & $* *$ & -0.089 & & 0.114 & & 0.384 & $* *$ & 0.020 & & -0.445 & * & 0.012 & & -0.468 & $* *$ & 0.071 \\
\hline 21 & 1.734 & $* *$ & 0.028 & $* *$ & 0.064 & $* *$ & 0.119 & $* *$ & 0.063 & $* *$ & 0.077 & $* *$ & 0.059 & $* *$ & -0.052 & $* *$ & 0.162 \\
\hline
\end{tabular}

12 This assumption is not unduly restrictive, since we did not observe any location changes during the period of analysis.

${ }^{13}$ With confidence levels indicated by stars calculated from Newey-West standard errors with one lag on the autoregression part of the estimates. 
The Spatial Covariance of the residuals, also scaled by the global variance is also presented on the following table:

Table 5: Spatial Covariance Estimates

\begin{tabular}{l|cccccc}
\hline \hline Product & \multicolumn{6}{|c}{ Distance in Km } \\
& 0.22 & 10.01 & 20.11 & 30.20 & 50.09 & 92.00 \\
\hline 1 & 0.518 & 0.540 & 0.651 & 0.782 & 0.491 & 0.705 \\
2 & 0.936 & 0.924 & 0.920 & 0.956 & 0.994 & 0.958 \\
3 & 0.889 & 0.912 & 0.922 & 0.908 & 0.923 & 0.889 \\
4 & 0.470 & 0.489 & 0.563 & 0.537 & 0.205 & 0.470 \\
5 & 0.380 & 0.534 & 0.452 & 0.266 & 0.399 & 0.365 \\
6 & 0.533 & 0.554 & 0.577 & 0.617 & 0.482 & 0.577 \\
7 & 0.448 & 0.456 & 0.411 & 0.464 & 0.464 & 0.414 \\
8 & 0.375 & 0.400 & 0.359 & 0.401 & 0.305 & 0.347 \\
9 & 0.557 & 0.579 & 0.561 & 0.597 & 0.437 & 0.538 \\
10 & 0.645 & 0.633 & 0.592 & 0.525 & 0.531 & 0.612 \\
11 & 0.469 & 0.463 & 0.451 & 0.554 & 0.537 & 0.470 \\
12 & 0.757 & 0.773 & 0.786 & 0.777 & 0.719 & 0.761 \\
13 & 0.761 & 0.765 & 0.752 & 0.826 & 0.900 & 0.821 \\
14 & 0.354 & 0.350 & 0.352 & 0.366 & 0.311 & 0.338 \\
15 & 0.385 & 0.395 & 0.443 & 0.435 & 0.407 & 0.398 \\
16 & 0.606 & 0.580 & 0.617 & 0.638 & 0.535 & 0.738 \\
17 & 0.777 & 0.776 & 0.725 & 0.744 & 0.854 & 0.789 \\
18 & 0.473 & 0.544 & 0.609 & 0.769 & 0.548 & 0.510 \\
19 & 0.452 & 0.461 & 0.489 & 0.553 & 0.401 & 0.433 \\
20 & 0.536 & 0.475 & 0.519 & 0.545 & 0.419 & 0.597 \\
21 & 0.583 & 0.586 & 0.493 & 0.495 & 0.630 & 0.562 \\
22 & 0.359 & 0.352 & 0.347 & 0.262 & 0.336 & 0.359 \\
\hline \hline
\end{tabular}

Just as in the case presented above, every one of the covariances is outside of the confidence interval for the null hypothesis of zero spatial covariance at that distance ${ }^{14}$. Thus, one can conclude that the relevant market for the considered merger is composed of all the cities envolved.

\section{Conclusions}

In this paper, we aim to identify the relevant geographic market for a proposed merger between two competing supermarket chains, CBD and PERALTA. In order to do so, we first reviewed the legal and theoretical aspects behind the determination of the relevant market, indicating the shortcomings of the analysis carried out by the Brazilian Antitrust Authority on its evaluation of the merger. This analysis decreed the geographic dimension of the relevant market to be separated on each of the municipalities on the shore of the Sao Paulo state.

After that, we proposed a methodology for determining the geographic dimension of the market by the estimation of a Spatial Covariance function. The estimation was carried out on a data sample

\footnotetext{
${ }^{14}$ We also carried out estimates with the first differences of the prices, and with a first difference version of the equation above. However, the results did not change and, for that reason, were not reported.
} 
constructed by collected data on 22 products for 43 supermarkets, for the period from January 2003 to February 2004.

Initially, we calculated spatial covariances for different distances, which indicated significant covariances at all distances, which indicated a single geographic market embracing the eight cities (Sao Vicente, Santos, Guaruja, Praia Grande, Cubatao, Mongagua, Itanhaem, Peruibe) which were held as separate markets.

Conscious of the shortcomings of the analysis, we extended the analysis trying to control for differences on the socio-economic variables of the cities, as well as differences on policies chosen by each supermarket chain, and seasonal patterns of consumption. The results confirmed the ones found on the previous section, indicating a single geographic relevant market for this merger.

\section{References}

[1] BROnNEnBERG, B., DHAR, S. K. and DUBE, J.-P. (2005) "Endogenous Sunk Costs and the Geographic Distribution of Brand Shares in Consumer Package Goods Industries" Working Paper University of Chicago GSB.

[2] CHEN, X., and CONLEY, T. (2001) "A New Semiparametric Spatial Model for Panel Time Series" Journal of Econometrics, 105, 59-83.

[3] CONLEY, T, (1999) "GMM Estimation with Cross-Sectional Dependence" Journal of Econometrics, 92, 1-45

[4] CONlEY, T. and TOPA, G. (2002) "Socio-Economic Distance and Patterns of Unemployment" Journal of Applied Econometrics, 17(4), 1-45.

[5] CRESSIE, N. A. C. (1993) Statistics for Spatial Data. Wiley Interscience, New York.

[6] ELZINGA, K. G. and HOGARTY, T. F. (1973) "The Problem of Geographic Market Definition in Antimerger Suits" Antitrust Bulletin 18 (1), 45-81.

[7] ELZINGA, K. G and HOGARTY, T.F. (1978) "The Problem of Geographic Market Definition Revisited" Antitrust Bulletin 23 (1), 1-18.

[8] GRENANDER, U. (1981) Abstract Inference. Wiley, New York.

[9] HOROWITZ, I. (1981) "Market Definition in Antitrust Analysis: A Regression-Based Approach" Southern Economic Journal 48(1), 1-16.

[10] KWOKA, J. E. and WHITE, L. J. (2003) The Antitrust Revolution: Economics, Competition and Policy. Cambridge: Cambridge University Press. 
[11] MotTA, M. (2004) Competition Policy: Theory and Practice.Cambridge: Cambridge University Press, 616p.

[12] SCHEFFman, D.T. and SPILlER, P. (1987) "Geographic Market Definition under the U.S. Department of Justice Merger Guidelines" Journal of Law and Economics, 30(1), 123-147.

[13] SHERWIN, R. A. (1993) "Comments on Werden and Froeb - Correlation, Causality and all that Jazz" Review of Industrial Organization, 8:355-358.

[14] SLADE, M. (1986) "Exogeneity Tests of Market Boundaries Applied to Petroleum Products" The Journal of Industrial Economics, 34(3) 291-303.

[15] STIGLER, G. J. and SHERWIN, R. A. (1985) "The Extent of the Market" Journal of Law and Economics, 28(3), 555-585.

[16] WALL, M. M. (2004) "A close look at the spatial structure implied by the CAR and SAR models" Journal of Statistical Planning and Inferencee 121, 311-324.

[17] WERDEN, G. J. (1998) "Demand Elasticities in Antitrust Analysis" Antitrust Journal 43, 363-414.

[18] Werden, G. J. and FROEB, L. M. (1993) "Correlation, Causality and all that Jazz: the inherent shortcomings of price tests for antitrust market delineation" Review of Industrial Organization, 8: 329-353

\section{Appendix}

\section{Appendix 1 - Stores Used}

\begin{tabular}{cccc}
\hline \hline Code & City & Longitude & Latitude \\
\hline 18 & Santos & -46.3231 & -23.959 \\
44 & Santos & -46.3091 & -23.9713 \\
52 & Guaruja & -46.2586 & -23.9919 \\
66 & Santos & -46.3083 & -23.9843 \\
69 & Praia Grande & -46.4125 & -24.0079 \\
102 & Guaruja & -46.2894 & -23.9566 \\
205 & Sao Vicente & -46.3702 & -23.9714 \\
692 & Santos & -46.3357 & -23.947 \\
694 & Sao Vicente & -46.3054 & -23.9407 \\
697 & Praia Grande & -46.4608 & -24.0188 \\
752 & Itanhaem & -46.7877 & 24.18392 \\
\hline \multicolumn{4}{c}{ Continues on Next Page } \\
\hline \multicolumn{4}{c}{}
\end{tabular}




\begin{tabular}{lccc}
\hline \hline Code & City & Longitude & Latitude \\
\hline 1008 & Guaruja & -46.2573 & -23.9966 \\
1217 & Peruibe & -46.9988 & -24.3206 \\
1740 & Cubatao & -46.4287 & -23.8729 \\
1741 & Cubatao & -46.4084 & -23.9271 \\
1742 & Santos & -46.3377 & -23.9583 \\
1743 & Santos & -46.3083 & -23.9814 \\
1744 & Cubatao & -46.4207 & -23.8825 \\
1745 & Santos & -46.3616 & -23.9349 \\
1746 & Sao Vicente & -46.4072 & -23.9549 \\
1747 & Santos & -46.3005 & -23.9769 \\
1748 & Mongagua & -46.6188 & -24.0927 \\
1749 & Guaruja & -46.2635 & -23.9883 \\
1750 & Santos & -46.3129 & -23.964 \\
1751 & Peruibe & -46.9936 & -24.3152 \\
1752 & Itanhaem & -46.7829 & -24.1805 \\
1753 & Praia Grande & -46.4205 & -24.0121 \\
1754 & Sao Vicente & -46.4925 & -23.9855 \\
1755 & Guaruja & -46.2779 & -23.9913 \\
1756 & Guaruja & -46.2715 & -23.9787 \\
1757 & Sao Vicente & -46.3767 & -23.9682 \\
1758 & Santos & -46.3187 & -23.9755 \\
1772 & Santos & -46.3216 & -23.9431 \\
1773 & Praia Grande & -46.4798 & -24.027 \\
1776 & Praia Grande & -46.4181 & -24.0033 \\
1777 & Sao Vicente & -46.3753 & -23.9554 \\
1813 & Guaruja & -46.2034 & -23.9857 \\
1821 & Guaruja & -46.2827 & -23.9396 \\
1853 & Guaruja & -46.237 & -23.9834 \\
2332 & Santos & -46.3442 & -23.9678 \\
2354 & Guaruja & -46.2468 & -23.988 \\
1348 & Santos & -46.3319 & -23.9577 \\
1327 & Praia Grande & -46.3986 & -23.9878 \\
\hline \hline & & &
\end{tabular}




\section{Appendix 2 - Histogram of Distances}

Figure 3: Histogram of Distances

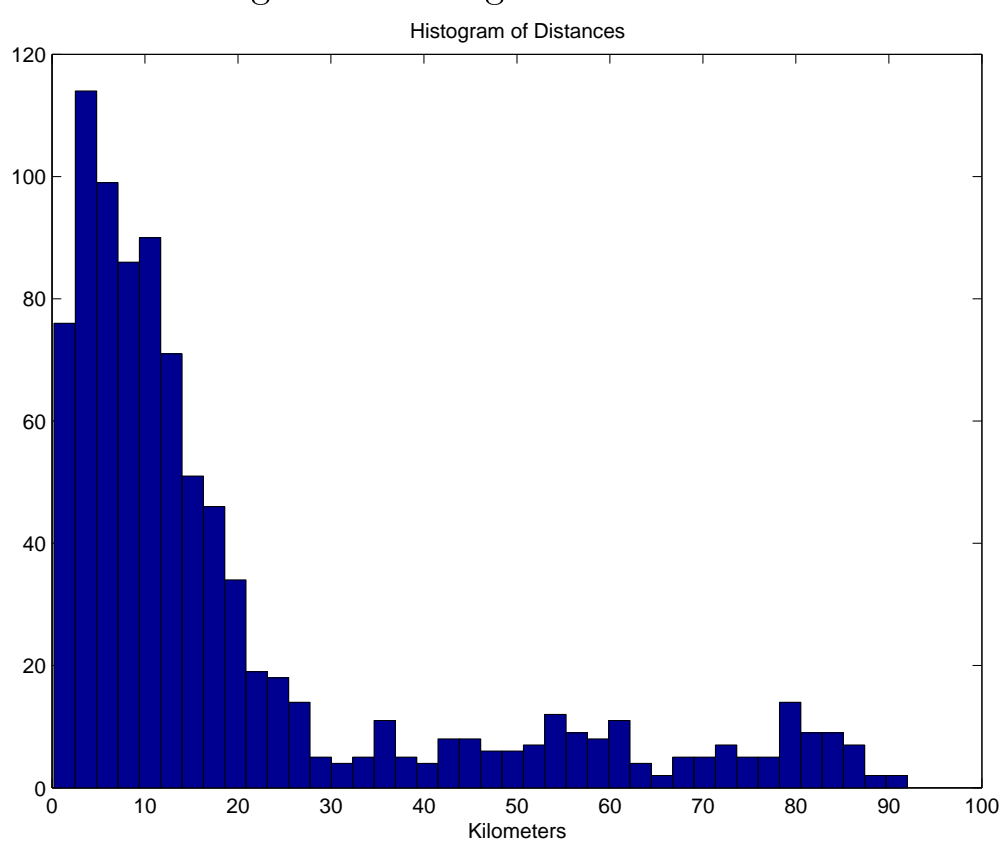

\section{Appendix 3 - Spatial Covariance Function}

Figure 4: Spatial Covariance Function

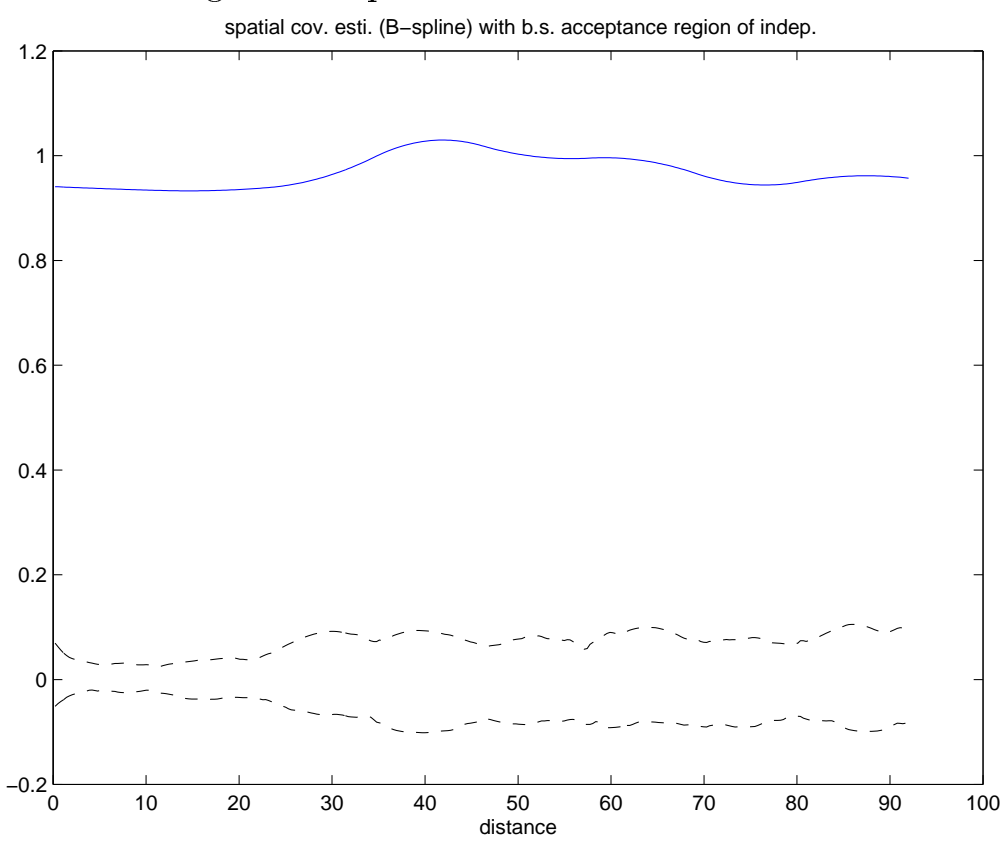




\section{Appendix 4 - Products - Descriptive Statistics}

\begin{tabular}{r|rrrrr}
\hline \hline Product & Mean & Std. Deviation & Minimum & Maximum & Number of Obs. \\
\hline 1 & 3.195 & 0.434 & 2.040 & 4.880 & 560 \\
2 & 1.147 & 0.170 & 0.660 & 1.480 & 602 \\
3 & 10.037 & 1.050 & 7.460 & 11.886 & 602 \\
4 & 2.153 & 0.227 & 1.760 & 2.950 & 588 \\
5 & 3.687 & 0.214 & 2.409 & 4.226 & 462 \\
6 & 0.757 & 0.060 & 0.618 & 0.910 & 602 \\
7 & 0.940 & 0.055 & 0.780 & 1.076 & 602 \\
8 & 0.776 & 0.046 & 0.660 & 0.884 & 602 \\
9 & 2.451 & 0.236 & 1.880 & 2.971 & 490 \\
10 & 8.800 & 1.110 & 6.488 & 12.050 & 602 \\
11 & 5.566 & 0.413 & 4.700 & 6.892 & 546 \\
12 & 2.324 & 0.210 & 1.801 & 2.906 & 602 \\
13 & 1.493 & 0.104 & 1.170 & 1.715 & 602 \\
14 & 1.749 & 0.131 & 1.331 & 2.118 & 602 \\
15 & 3.624 & 0.188 & 2.800 & 4.131 & 574 \\
16 & 2.806 & 0.188 & 2.205 & 3.640 & 574 \\
17 & 0.580 & 0.107 & 0.343 & 0.968 & 476 \\
18 & 1.375 & 0.150 & 0.967 & 1.808 & 420 \\
19 & 10.452 & 1.161 & 7.514 & 13.430 & 532 \\
20 & 11.050 & 1.178 & 8.451 & 14.040 & 532 \\
21 & 1.790 & 0.106 & 1.530 & 1.995 & 588 \\
22 & 0.884 & 0.052 & 0.690 & 0.990 & 574 \\
\hline \hline
\end{tabular}

